\title{
Bartonella elizabethae
}

National Cancer Institute

\section{Source}

National Cancer Institute. Bartonella elizabethae. NCI Thesaurus. Code C86185.

A species of aerobic, Gram-negative, rod shaped bacteria assigned to the phylum

Proteobacteria. This species is nonmotile, catalase, oxidase, urea, and indole negative and is hemolytic. B. elizabethae causes endocarditis. 